\title{
Pulling Back the Curtain on Microbial Sulfur Dynamics in a Mine Tailings Impoundment
}

\author{
K.J. Whaley-Martin ${ }^{1}$, L.-X. CheN $^{2}$, T. COlenbrander

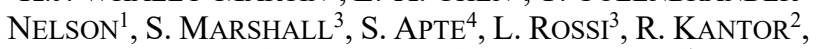 \\ L. TWIBLE ${ }^{1}$, J. BANFIELD ${ }^{2}$, L.A. WARREN ${ }^{1 *}$ \\ ${ }^{1}$ University of Toronto, Ontario Canada; kelly.martin@utoronto.ca; \\ tara.nelson@utoronto.ca; lauren.twible@mail.utoronto.ca; \\ lesley.warren@utoronto.ca \\ ${ }^{2}$ University of California, Berkeley, California, USA; \\ linxingchen@berkeley.edu; rkantor@berkely.edu; \\ jbanfield@berkeley.edu \\ ${ }^{3}$ McMaster University, Ontario, Canada; marshs1@mcmaster.ca; \\ rossil@mcmaster.ca
}

${ }^{4}$ CSIRO Land and Water, NSW, Austrailia; Simon.apte@csiro.au

Many tailings impoundments contain high concentrations of reduced sulphur species that may eventually oxidize causing acidity generation. There is a significant gap in knowledge regarding the microorganisms that govern sulphur cycling within these circumneutral systems, which impedes prediction and mitigation of acidity generation, oxygen consumption as well as potential toxicological implications downstream. The water cap of an active tailings impoundment ( $38 \mathrm{~m}$ depth) in Canada was studied through complementary applications of microbial metagenomics and aquatic geochemistry including but not limited to $\mathrm{S}$ and $\mathrm{N}$ speciation for over half a decade (2014-2018). The integrated approach, combining in depth geochemistry, 16SrRNA (community composition) and metagenomics (metabolic functionality) applied in this study provides one of the first in depth insights into the complex microbial dynamics that govern these types of globally widespread biogeochemical environments. The previously uncharacterized microbiome within the stratified water column of the tailings impoundment ( $\mathrm{pH} \sim 7$ to 4 ) bore little resemblance to those identified from better-characterized acid mine drainage sites globally. The gene repertoires of the bacterial communities found in this study, reveal they are well adapted for aerobic and anaerobic autotrophic sulfur cycling and heterotrophy. The relative proportions of families with metabolic repertoires for sulfur cycling (Sox and/or Dsr genes) (i.e. Halothiobacillacea, Burkholderiaceae and Hydrogenophilaceae) proved to be sensitive indicators to developing shifts in water geochemistry, such as accelerating acidity generation from circum-neutral conditions. In particular, the presence of the genus Halothiobacillus, not previously identified to be important in AMD generation, was a reliable indicator of the early phases of acidity generation in the oxidized epilimnetic portions of this tailings impoundment. 